\title{
Periductal Stromal Tumor of the Breast: A Case Report and Review of the Literature
}

\author{
Gökçe Askan ${ }^{1}$, Erkin Arıbal², Gamze Ak ${ }^{1}$, Handan Kaya ${ }^{1}$ \\ ${ }^{1}$ Department of Pathology, Marmara University Hospital, İstanbul, Turkey \\ ${ }^{2}$ Department of Radiology, Marmara University Hospital, İstanbul, Turkey
}

\begin{abstract}
We present a woman aged 50 years who underwent a Tru-cut biopsy for a BI-RADS 4 lesion on her right breast and received a histopathology diagnosis of a fibroadenoma. In her one year follow-up, the lesion had progressed and she underwent an excisional biopsy. Her final diagnosis was a periductal stromal tumor. Periductal stromal tumor is an extremely rare and different entity from phylloides tumor, which makes appropriate diagnosis difficult in Tru-cut biopsy and care should be taken. Lesion progression of should require a re-biopsy. Their tendency to recur warrants follow-up. We believe that radiologic, pathologic, and clinical correlation is key in decision-making and diagnosis of these tumors.
\end{abstract}

Keywords: Breast neoplasm, periductal stromal tumor, ultrasound, mammography

\section{Introduction}

Periductal stromal tumor (PST) is an extremely rare, low-grade neoplasm that arises from breast connective tissue. It has biphasic morphology with benign ducts and a sarcomatous stroma with no specific clinical or radiologic findings, which makes it difficult to diagnose (1-4). It was classified as a different entity by the World Health Organization (WHO) in 2002 because of lack of phylloides architecture. PST has a tendency to recur if excised incompletely and can be transformed to sarcomas, which is why surgery with safe margins is recommended $(2,3,5)$. Herein, we present the radiologic features and histopathology of this case especially to emphasize the importance of diagnosis using Tru-cut biopsy with radiologic-pathologic correlation, and to discuss the differential diagnosis of periductal stromal tumor of the breast.

\section{Case Presentation}

A woman aged 50 years who has yearly mammography screening had a new mass in her mammogram. Her mammogram showed a mass of $7 \mathrm{~mm}$ at its widest diameter in the upper inner quadrant of the right breast, which did not exist on her prior mammograms (Figure 1a). The mass was oval with circumscribed margins and showed equal density. An ultrasound (USG) examination showed an oval mass in parallel orientation with circumscribed margins in the upper inner quadrant of the right breast. The mass was $6.8 \times 6.0 \mathrm{~mm}$ in size (Figure $1 \mathrm{~b}$ ). The lesion was de novo and interpreted as BIRADS 4a and a biopsy was recommended. A Tru-cut biopsy was performed and interpreted as fibroadenoma with intraductal hyperplasia by an external pathology clinic. One year later, her routine screening mammogram showed indistinct margins (Figure 1c). A USG examination showed similar features to the prior examination but the size had enlarged to $9.0 \mathrm{x}$ $7.5 \mathrm{~mm}$ (Figure 1d). Rebiopsy of the lesion was planned. Reinterpretation of her prior biopsy specimen showed a tumor with biphasic proliferation with minimal atypical spindle cells that surrounded open ducts and tubules with lack of leaf-like growth pattern. A multidisciplinary breast board recommended an excisional biopsy depending on the new interpretation and enlargement of the lesion. An excisional biopsy after guide-wire localization was performed. Excisional biopsy 13 months after the first Tru-cut biopsy showed a $70 \mathrm{x} 60$ x $30 \mathrm{~mm}$ specimen; by multiple sectioning, lobulated lesion that was a beige in color and $8 \mathrm{~mm}$ in diameter. The lesion was $5 \mathrm{~mm}$ distant to the nearest surgical margin.

Microscopically, for both previous Tru-cut biopsies (Figure 2a) and present excisional biopsy (Figure 2b), the tumor had biphasic proliferation and a multinodular growth pattern composed of spindle cells without significant atypia, cuff formations around open tubules without leaf-like patterns, and occasional mitoses (1/10 HPF). Epithelial components had a double layer or hyperplastic features without atypia and leaf-like growth pattern. The resection margins were negative and the closest distance between tumor and nearest resection margin was $5 \mathrm{~mm}$. In immunohistochemistry staining, ductal cells were positive for estrogen receptor (ER), progesterone receptor (PR), 

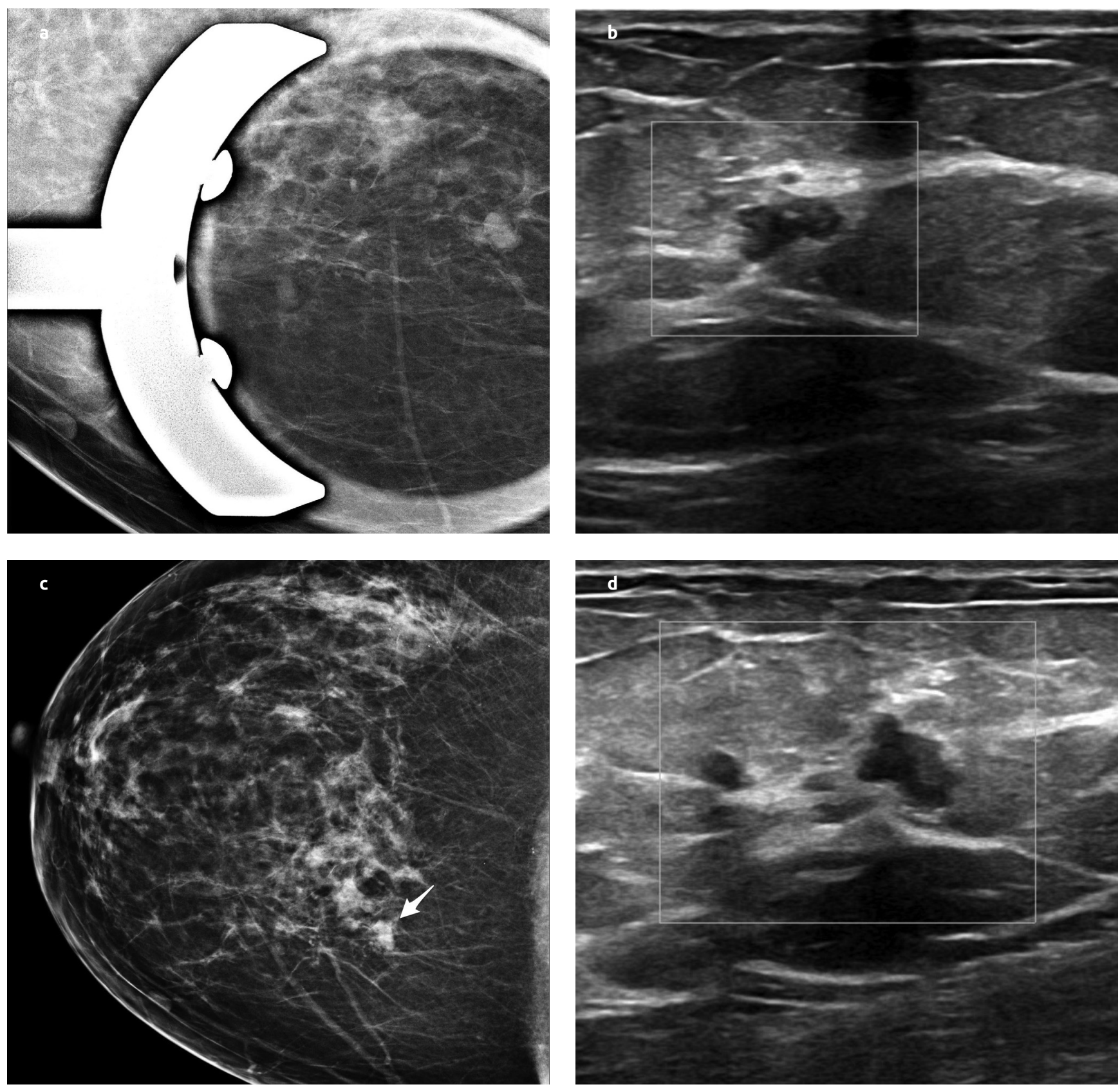

Figure 1. a-d. (a) RCC spot mammogram shows a mass of equal density with an oval shape and circumscribed margins. The margins are lobulated (b) USG image of the lesion. A parallel oriented, oval, and well-circumscribed hypoechoic mass with no posterior features is seen (c) The same mass as in Figure 1 one year later; the margins are indistinct (d) The mass has the same USG features with Figure $1 \mathrm{~b}$ but shows significant enlargement. Lobulation of the margins is more prominent

GCDFP15, CK19 and CK14; stromal cells were only positive with CD10 and CD34 (Figure 3). Proliferation index (Ki-67) was 1\%. According to the histomorphologic and immunohistochemical findings the diagnosis of low-grade periductal stromal tumor was established.

\section{Discussion and Conclusion}

Periductal stromal tumor was previously accepted as a synonym for phylloides tumor, but it was recently classified as a distinct entity by the WHO in 2002 because of lack of leaf-like growth pattern $(1,2)$. Unlike phylloides tumor, the incidence is higher in perimenopausal and post-menopausal women. Similar to phylloides tumor, it has a tendency for local recurrence when incompletely excised and can tion with spindle tumor cells around open ducts, tubules, and cellular sarcomatous stroma $(5,6)$. The histologic criteria for PST according to the Armed Forces Institute of Pathology (AFIP) include: predominantly sarcomatous spindle cell stromal proliferation around open ducts and tubules, lack of leaf-like growth pattern, one or more nodules that can be separated by adipose tissue, mitotic activity equal to or more than 3 in 10 high power fields (HPF) and infiltration into surrounding adipose tissue $(2,3)$. The histologic grading depends on atypia and mitotic count ranges from low to high grade. Tumor cells are only positive with CD34, CD10, and lacks CD117, S-100, ER, and PR expression $(2,7)$. PST is a tumor of intermediate behavior and resection with significant margin is considered sufficient for treatment. Adjuvant chemotherapy or radiotherapy is not recommended. 

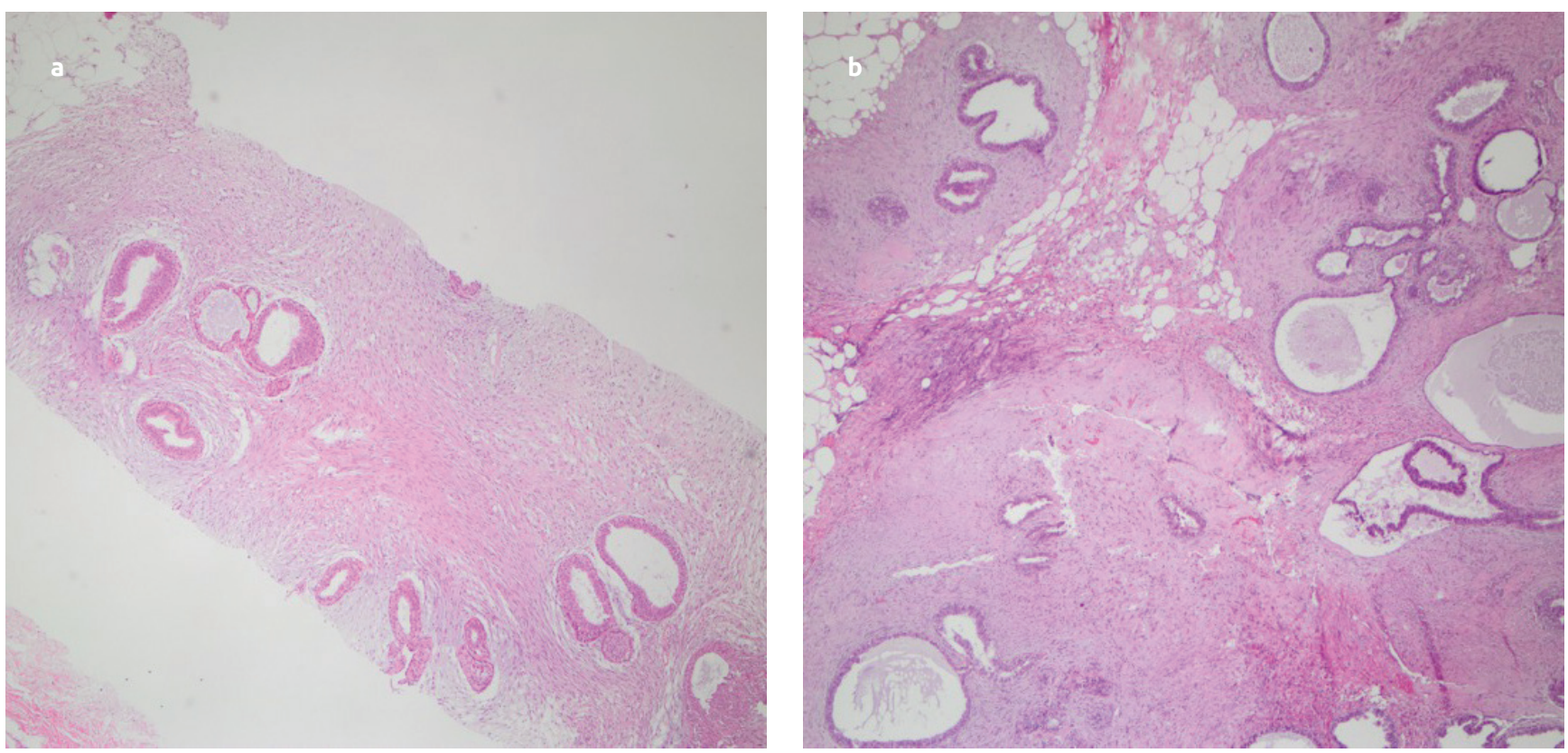

Figure 2. a, b. (a) The tumor had biphasic proliferation and a multinodular growth pattern and was composed of spindle cells without significant atypia, cuff formations around open tubules without leaf-like pattern (X40) (b) Epithelial components had a double layer or hyperplastic features without atypia and leaf-like growth pattern (X100)

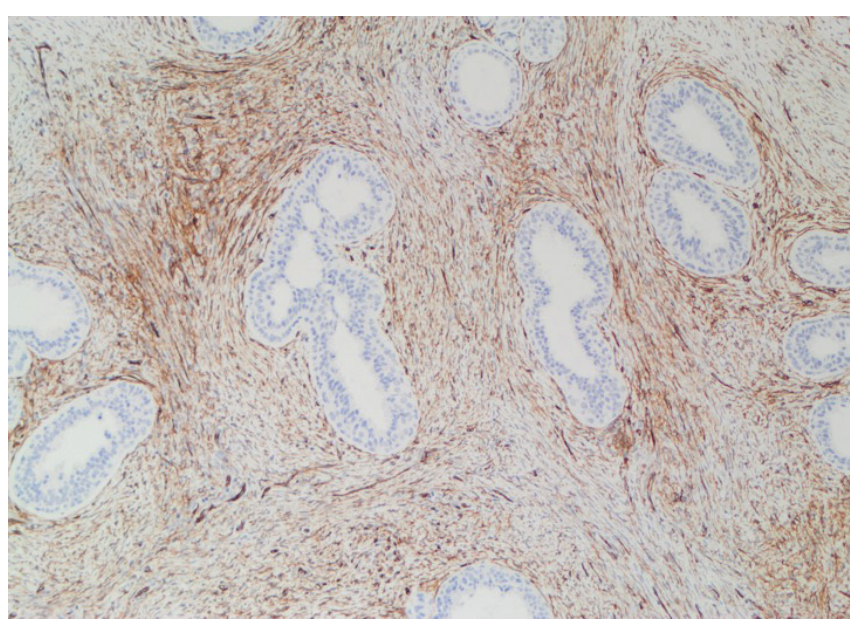

Figure 3. Stromal cells were positive with CD34 (X100)

In differential diagnosis several tumors should be thought; firstly phylloides tumor, then spindle cell carcinoma, myoepithelial carcinoma and other breast sarcomas (1). The main difference from phylloides tumor is the lack of leaf-like pattern in PST. The differential diagnosis of spindle cell carcinoma is important because of different targeted therapy and immunohistochemistry can also be helpful; tumor cells are positive with CK5, CK14, p63, and negative with CD34 (8-10). Breast sarcomas have highly pleomorphic nuclei, abundant mitotic figures, and positive with CD10 and Vimentin, and negative with CD34. Myoepithelial carcinomas have an infiltrative growth pattern with biphasic or glandular pattern, are highly pleomorphic, mitotically active, and positive for Vimentin, SMA, S100, p63 and CK14 (1, 10). In the present case, tumor composed of minimal atypical spindle cells surrounded open ducts and tubules without a leaf-like growth pattern. Spindle cells were only positive with CD10 and CD34, and the proliferation index was $1 \%$, which was compatible with PST.
As a result, PST is an extremely rare entity, and shows similar symptoms with other benign and malignant breast tumors, absence of specific radiologic findings make the diagnosis difficult (2). Extensive tumor sampling and additional immunohistochemistry should be performed for appropriate diagnosis. Before making a decision, other spindle cell tumors should be taken in consideration in the differential diagnosis because of different targeted therapy.

There are few case reports published in the English literature because PST is a rare entity $(3,11-13)$. There is little information about the radiologic features of these lesions; the only two separate cases reported in the literature roughly describe the radiologic features without using definitive images $(12,13)$. Although the descriptions and images are not clear in these reports, the lesions seem to have similar radiologic features $(12,13)$. The radiologic features of our case were similar to a fibroadenoma. However, de novo presentation after middle age and enlargement during follow-up should raise suspicion in such cases. To our knowledge, this is the first detailed report of PST with USG and mammographic findings.

We believe that radiologic, pathologic, and clinical correlation are key in decision making and the diagnosis of these tumors.

Informed Consent: Informed consent was obtained from patients who participated in this study.

Peer-review: Externally peer-reviewed.

Author Contributions: Concept - G.A., H.K.; Design - G.A., H.K., E.A.; Supervision - H.K., E.A.; Materials - G.A., H.K., G.Ak, E.A.; Data Collection - G.A., G.Ak, E.A.; Anlaysis and Interpretation - H.K., E.A.; Literature Review - G.A., G.Ak, E.A.; Writing - G.A., G.Ak; Critical Review - H.K., E.A.

Conflict of Interest: No conflict of interest was declared by the authors.

Financial Disclosure: The authors declared that this study has received no financial support. 


\section{References}

1. Tavassoli FA, Devilee P, editors. World Health Organization: In World Health Organization Classification of Tumours 2003, Pathology and Genetics Tumours of the Breast and Female Genital Organs. Lyon: IARC Press; 2003.p.101-102.

2. Burga AM, Tavassoli FA. Periductal stromal tumor: A rare lesion with low-grade sarcomatous behavior. Am J Surg Pathol 2003; 27:343-348. (PMID: 12604890) [CrossRef]

3. Rao AC, Geetha V, Khurana A. Periductal stromal sarcoma of breast with lipoblast-like cells: A case report with review of literature. Indian J Pathol Microbiol 2008; 51:252-254. (PMID: 18603698) [CrossRef]

4. Pandey M, Mathew A, Abraham EK, Rajan B. Primary Sarcoma of the Breast. J Surg Oncol 2004; 87:121-125. (PMID: 15334638) [CrossRef]

5. Callery CD, Rosen PR, Kinne DW. Sarcoma of the breast: a study of 32 patients with reappraisal of classification and therapy. Ann Surg 1985; 201:527-532. (PMID: 3977455) [CrossRef]

6. Oberman HA, Nosanchuk JS, Finger JE: Periductal stromal tumors of breast with adipose metaplasia. Arch Surg 1969; 98:384-387. (PMID: 5766289) [CrossRef]

7. Tomas D, Janković D, Marusić Z, Franceschi A, Mijić A, Kruslin B. Lowgrade periductal stromal sarcoma of the breast with myxoid features: immunohistochemistry. Pathol Int 2009; 59:588-591. (PMID: 19627544)
[CrossRef]

8. Tse GM, Tan PH, Lui PC, Putti TC. Spindle cell lesions of the breast: The pathologic differential diagnosis. Breast Cancer Res Treat 2008; 109:199207. (PMID: 17636400) [CrossRef]

9. Lee AH. Recent developments in the histological diagnosis of spindle cell carcinoma, fibromatosis and phyllodes tumour of the breast. Histopathology 2008; 52:45-57. (PMID: 18171416) [CrossRef]

10. Hungermann D, Buerger H, Oehlschlegel C, Herbst H, Boecker W. Adenomyoepithelial tumours and myoepithelial carcinomas of the breast: $\mathrm{A}$ spectrum of monophasic and biphasic tumours dominated by immature myoepithelial cells. BMC Cancer 2005; 5:92-101. (PMID: 16050957) [CrossRef]

11. Masbah O, Lalya L, Mellas N, Bekkouch I, Allaoui M, Hassouni K, Kebdani T, Regragui A, Benjaafar N, Elgueddari BK. Periductal stromal sarcoma in a child: a case report. J Med Case Rep 2011; 5:249. (PMID: 21714873) [CrossRef]

12. Lan Y, Zhu J, Liu J, Yang H, Jiang Y, Wei W. Periductal stromal sarcoma of the breast: A case report and review of the literature. Oncol Lett 2014; 8:1181-1183. (PMID: 25120682) [CrossRef]

13. Chavet X, Van Eeckhout P, Ska S, Blaude M, Moreaux O, Feoli F. Periductal stromal tumor of the breast. A case report. J Gynecol Obstet Biol Reprod (Paris) 2010; 39:503-506. (PMID: 20547011) [CrossRef] 